\title{
Diagnostic Methods for Prevention of Anal Cancer and Characteristics of Anal Lesions Caused by HPV in Men with HIV/AIDS
}

\author{
Araiz Cajueiro Carneiro Pereira, Heló́sa Ramos de Lacerda and Romualda Castro do Rêgo Barros \\ Postgraduate Course in Tropical Medicine; Infectious and Parasitic Diseases Clinic of the University Hospital; Colposcopy and Lower Genital \\ Tract Sector (SCTGI) of the University Hospital; Federal University of Pernambuco; Recife, PE, Brazil
}

\begin{abstract}
Abnormalities found with anuscopy under colposcopic vision, anal cytology and anal biopsy were evaluated in 21 men with human immunodeficiency virus/acquired immunodeficiency syndrome (HIV/AIDS) at the Federal University of Pernambuco Hospital in Brazil. Mean age was 38.4 \pm 6.0 years, and mean time of HIV infection was $8.3 \pm 5.1$ years; 95.2\% of the patients had been on highly active antiretroviral therapy (HAART) for an average of $6.6 \pm 4.5$ years. Mean CD4+ cell count was $482.2 \pm 173.75$ cells $/ \mathrm{mm}^{3}$, and $\mathbf{8 0 . 9} \%$ presented a $\mathrm{HIV}$ viral load of $<5,000$ copies/mL. Reported sexual preference was $52.4 \%$ homosexuals, $28.6 \%$ bisexuals, and $19.0 \%$ heterosexuals; $81 \%$ reported having had receptive anal intercourse and $\mathbf{6 1 . 9 \%}$ reported more than 10 sexual partners of the same sex. Results of anuscopy under colposcopic vision revealed 17 (81.0\%) low-grade lesions and/or condylomata or micropapillae and four (19.0\%) high-grade lesions with or without condylomata. Among the 21 anal cytology examinations, seven (33.3\%) revealed low-grade squamous intraepithelial lesions (LSIL); three (14.3\%) presented atypical squamous cells of undetermined significance (ASCUS) and $11(52.4 \%)$ were normal. Seventeen patients were submitted to anal biopsy with the following findings: three patients (17.6\%) with normal epithelium, one (5.9\%) with infection by HPV, three (17.6\%) with condylomatas, two (11.8\%) with AIN 1, four (23.6\%) with AIN 2, three (17.6\%) with AIN 3, and one (5.9\%) with PAIN 2. Anuscopy under colposcopic vision was found to be useful for detecting anal lesions and for guiding anal biopsies. Anal cytology was less useful, as it underestimated the frequency of lesions.
\end{abstract}

Key-Words: HIV/AIDS, HPV, anuscopy, anal cytology, anal biopsy.

Individuals infected by the human immunodeficiency virus (HIV) have a high risk of infection by human papillomavirus (HPV), as well as a high incidence of anal intraepithelial neoplasia (AIN) and anal cancer caused by HPV [1]. The potentialization of the effects of HIV by HPV is not fully understood [2]. These changes may be due to a deficient response of the immune system due to HIV or direct interaction between HIV and HPV [2-4].

In recent years, strong evidence for the participation of HPV in the pathogenesis of anogenital cancer has been found. High-risk HPVs are found in more than $99.7 \%$ of cervical squamous cell carcinomas. In anal cancer patients, the frequency of detection of high-risk HPVs ranges from 70 to $100 \%$, depending on origin, location, sexual orientation and HIV status [5].

Anal cancer has similar biological properties to cervical cancer. Like the cervix, the anal canal has a transformation zone in which the columnar epithelium of the rectum joins the squamous epithelium of the anus. As in the cervical transformation zone, the anorectal junction is a common site of anal HPV infection and development of AIN, a potential precursor of anal cancer. Anal intraepithelial and cervical neoplasias present the same histological patterns, are associated with the same types of HPV, and have a similar natural history $[6,7]$.

Received on 6 April 2008; revised 20 July 2008.

Address for correspondence: Dr. Araiz Cajueiro Carneiro Pereira. Avenida Getúlio Vargas, 553 - Bairro Novo. Zip code: 53030-010. Olinda, PE, Brazil. E-mail: araiz@uol.com.br.

The Brazilian Journal of Infectious Diseases 2008;12(4):293-299. (C) 2008 by The Brazilian Journal of Infectious Diseases and Contexto Publishing. All rights reserved.
Transmission and acquisition of HPV infection occurs through the mucocutaneous epithelial tissue, as a result of lesions that occasionally are provoked by the sexual act, or through the thin epithelial layers, such as the transition zone of the cervix and the anus. The virus becomes stable in the undifferentiated basal layer of the epithelium, a region that HPV requires to begin infection. The life cycle of HPV depends on continuous replication of the host cell; the virus uses the machinery of the infected cell for replication of its genetic material and expression of oncoproteins [5].

In view of the biological and epidemiological similarities between cervical and anal squamous cancinomas mediated by HPV and the significant reduction in the incidence of cervical cancer after the implementation of oncotic cytology in recent decades $[1,8]$, anal examination of high-risk groups, such as HIV-positive patients has been recommended [1,811]. Oncotic cytology and anuscopy under colposcopic vision are the main techniques recommended for the detection of anal cancer.

The technique of anuscopy under colposcopic vision is similar to that of cervical colposcopy [12]. Suspicious areas become acetowhite with the application of acetic acid, and vascular alterations manifest as punctations and mosaics. Abnormal epithelium does not stain dark brown with lugol (iodine solution) staining, as observed in normal squamous epithelium [1]. Anuscopy under colposcopic vision is extremely valuable for determining the extent and characteristics of anal and perianal intraepithelial lesions [13].

We compared various methods to detect anal lesions mediated by HPV (anuscopy under colposcopic vision, anal cytology and anal biopsy) and examined the characteristics of these lesions in a group of men with HIV/AIDS. 


\section{Material and Methods}

We made a case series study in the Infectious and Parasitic Diseases Outpatient Clinic and in the Colposcopy and Lower Genital Tract Department (CIGTD) of the University Hospital of the Federal University of Pernambuco (HC-UFPE) from July to November 2006. The study population consisted of 21 male patients with HIV/AIDS who presented anal lesions detected by anuscopy under colposcopic vision, with or without abnormalities based on anal cytology and biopsy. These patients were part of a group of 60 individuals with HIV/ AIDS enrolled in a prevalence study of anal lesions caused by HPV. Patients received information about their examination, and those who agreed to take part in the study signed an informed consent document.

After the questionnaire had been filled out, the patients' clinical records were consulted to record their latest T CD4+ lymphocyte counts and viral load data. T CD4+ lymphocyte counts were measured by the flow cytometry method. The viral load, based on HIV (RNA-HIV) ribonucleic acid particles, was quantified by the nucleic acid sequencebased amplification (NASBA) method.

Anal cytology was performed with a cytological brush, moistened with a saline solution, introduced into the anal canal to a depth of between 3 and $5 \mathrm{~cm}$, rotated $360^{\circ}$ and removed in a spiral movement. The material adhering to the brush was rolled onto a dry transparent glass slide and conditioned in a cylindrical recipient containing $95^{\circ}$ ethyl alcohol as a fixing solution. The slides were stained by the Papanicolaou pap-smear method (with hematoxylin-eosin dye) and examined under light microscopy by a single cytopathologist. The cytological findings were classified in accordance with the Bethesda system (2001) for the classification of preinvasive cervical and anal lesions [14]. The intraepithelial anal lesions were classified as low-grade squamous intraepithelial lesions (LSIL), high-grade squamous intraepithelial lesions (HSIL) or atypical squamous cells of undetermined significance (ASCUS).

After the cytology collection, anuscopy was performed with a colposcope; the patient was maintained in the right lateral decubitus position, with knees bent over the thighs. The anuscope was lubricated with aqueous gel and inserted; after removal of the embolus, $3 \%$ acetic acid was applied and the area was magnified and visualized with the colposcope. This procedure allowed identification of changes in the epithelium, characterized as a flat or dense acetowhite epithelium, associated or not with fine or thick punctuation/mosaicism. Next, Schiller's test was performed (application of a lugol solution). The anuscopic features were assessed using Barcelona Colposcopic Terminology [15].

Anuscopic findings suggestive of an anal lesion were biopsied. The biopsy procedure was guided by the colposcope with the aid of a Gaylor-Medina clamp, under local anesthesia using $2 \%$ lidocaine gel, without a vasoconstrictor. Whenever an extensive macroscopically-visible lesion was found on the anal margin, a biopsy was conducted in the operating room under rachidian anesthesia. The histological evaluation was always made carried by the same pathologist and classified as one of the following: normal, atypical related to infection by HPV, condyloma acuminatum or intraepithelial anal neoplasia grade I, II or III [16].

The Bethesda System terminology (2001) is also applied to histological nomenclature; it classifies condylomata/HPV and AIN 1 as a low-grade squamous intraepithelial lesion and AIN 2 and 3 as a high-grade squamous intraepithelial lesion [13]. When we found lesions of different grades in the same patient, the highest grade lesion was considered. The anal biopsy was used to grade the anal and perianal lesions.

This study was approved by the Ethics in Research Committee of the Federal University of Pernambuco's Center of Health Sciences, protocol number 109/2006 - CEP/CCS.

\section{Results}

Age, clinical status of HIV infection and sexual preference of the patients are shown in Table 1. The mean age was $38.4 \pm$ 6.0 years, the mean time since HIV infection diagnosis was 8.3 \pm 5.1 years and HAART use was reported by $95.2 \%$, with a mean duration of $6.6 \pm 4.5$ years. The mean T CD4+ lymphocyte count was $482.2 \pm 173.75$ cells $/ \mathrm{mm}^{3} ; 80.9 \%$ had a viral load below 5,000 copies $/ \mathrm{mL}$. Sexual behavior was distributed as follows: 11 (52.4\%) were homosexuals, six (28.6\%) were bisexuals and four (19.0\%) were heterosexuals. Eighty-one percent reported having had receptive anal intercourse and $61.9 \%$ reported having had more than 10 sexual partners of the same sex during their lifetime.

\section{Results of Anuscopy Under Colposcopic Vision}

Among the 21 patients with abnormal anuscopy, 10 (47.6\%) presented low-grade anal lesions, demonstrated by flat acetowhite epithelium, negative iodine or with partial capitation of iodine at the anal squamous-columnar junction, associated or not with a fine mosaic, fine punctuation, micropapillae and concurrent endoanal and perianal condyloma acuminatum. Only one patient (4.8\%) presented micropapillae at the anal squamous-columnar junction without acetowhite epithelium. Six patients (28.6\%) presented only condylomatous lesions (Figure 1); one of them had a giant condyloma (Figure 2, Table 2).

Four (19.0\%) patients presented high-grade anal lesions, three of whom presented an area of dense acetowhite ephitelium associated with a thick mosaic. One patient presented concomitant high-grade anal lesions and endo and perianal condylomata (Table 2).

\section{Anal Oncotic Cytology}

Among the 21 patients with abnormal anuscopic findings, 11 (52.4\%) presented normal cytological results, seven (33.3\%) presented LSIL and three (14.3\%) presented ASCUS (Figures 3 and 4 , Table 3). 
Table 1. Distribution of the 21 patients according to age, clinical state of HIV infection and sexual behavior.

\begin{tabular}{|c|c|c|c|c|}
\hline Characteristics & $\mathbf{N}$ & $\%$ & Mean & SD \\
\hline \multicolumn{5}{|l|}{ Age (years) } \\
\hline $28-40$ & 12 & 57.1 & 38.4 & \pm 6.0 \\
\hline $41-51$ & 9 & 42.9 & & \\
\hline \multicolumn{5}{|c|}{ Time of HIV diagnosis (years) } \\
\hline $0-5$ & 6 & 28.6 & 8.3 & \pm 5.1 \\
\hline $6-10$ & 9 & 42.8 & & \\
\hline $11-18$ & 6 & 28.6 & & \\
\hline \multicolumn{5}{|l|}{ Antiretroviral use } \\
\hline Yes & 20 & 95.2 & & \\
\hline No & 1 & 4.8 & & \\
\hline \multicolumn{5}{|c|}{ Time of use of antiretroviral (years) } \\
\hline $1-5$ & 6 & 30.0 & 6.6 & \pm 4.5 \\
\hline $6-9$ & 10 & 50.0 & & \\
\hline$\geq 10$ & 4 & 20.0 & & \\
\hline \multicolumn{5}{|l|}{ CD4+ (cells/mm³) } \\
\hline$<200$ & 1 & 4.8 & 482.2 & \pm 173.75 \\
\hline $200-500$ & 8 & 39.1 & & \\
\hline$>500$ & 12 & 57.1 & & \\
\hline \multicolumn{5}{|c|}{ Viral load (copies of RNA/mL) } \\
\hline$<5.000$ & 17 & 80.9 & & \\
\hline $5.000-30.000$ & 3 & 14.3 & & \\
\hline$>30.000$ & 1 & 4.8 & & \\
\hline \multicolumn{5}{|l|}{ Sexual preference } \\
\hline Homosexual & 11 & 52.4 & & \\
\hline Bisexual & 6 & 28.6 & & \\
\hline Heterosexual & 4 & 19.0 & & \\
\hline \multicolumn{5}{|c|}{ Receptive anal intercourse } \\
\hline Yes & 17 & 81.0 & & \\
\hline No & 4 & 19.0 & & \\
\hline \multicolumn{5}{|c|}{ Numbers of partners of same sex (during life) } \\
\hline None & 4 & 19.0 & & \\
\hline $1-5$ & 3 & 14.3 & & \\
\hline $6-10$ & 1 & 4.8 & & \\
\hline More than 10 & 13 & 61.9 & & \\
\hline
\end{tabular}

$\mathrm{SD}=$ standard deviation.

\section{Anal Biopsy}

Among the 21 patients indicated for biopsy due to abnormal anuscopic findings, four refused to undergo the procedure. Among the 17 on whom the biopsies were performed, three (14.3\%) proved normal, six (28.6\%) presented low-grade anal lesions caused by HPV-infection, condylomata (Figure 5A and B) and AIN 1, and eight (38.1\%) presented high-grade anal lesions, represented by AIN 2, AIN 3 and PAIN 2 (Figure 6, Table 3).

Correspondence Between the Colposcopic Anuscopy Exams, anal Cytology and Biopsy

A comparison of the results of anuscopy under colposcopic vision, anal cytology and anal biopsy is shown in Table 3 . Among the 10 (47.6\%) patients with anuscopic findings of a low-grade anal lesion, only four (19.0\%) presented a cytological diagnosis of LSIL. Nine of these patients were submitted to biopsy, of which two (9.5\%) had low-grade anal lesions and four (19.0\%) had high-grade anal lesions.

Among the six (28.6\%) patients with isolated condylomata, the cytology proved to be abnormal in two (9.5\%) cases. The histological findings were low-grade anal lesions in three (14.3\%) and high-grade anal lesions in one (4.8\%). In one patient with micropapillae at the anal squamous-columnar junction seen in anuscopy, the cytology was normal and the biopsy showed an atypical pattern due to infection by HPV.

Four (19.0\%) patients presented anuscopic findings suggestive of high-grade anal lesions. Anal cytology identified two (9.5\%) diagnoses of LSIL and two (9.5\%) of ASCUS. Three (14.3\%) of these patients were submitted to biopsy and all three presented high-grade anal lesions. The four individuals who refused the biopsy had a normal cytological result and ASCUS. 
Figure 1. Endoanal condylomata.

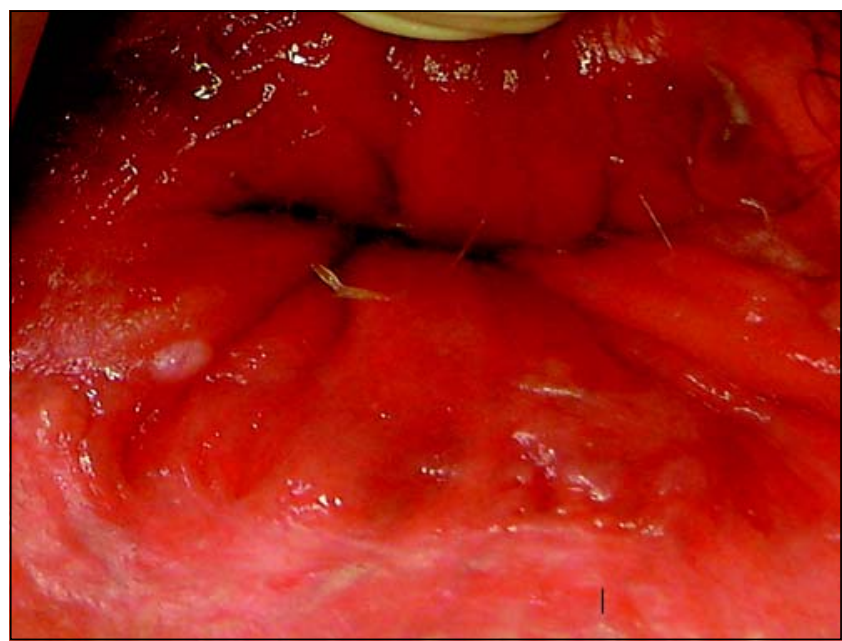

Figure 3. Anal cytology of atypical squamous cells of undetermined significance-ASCUS.

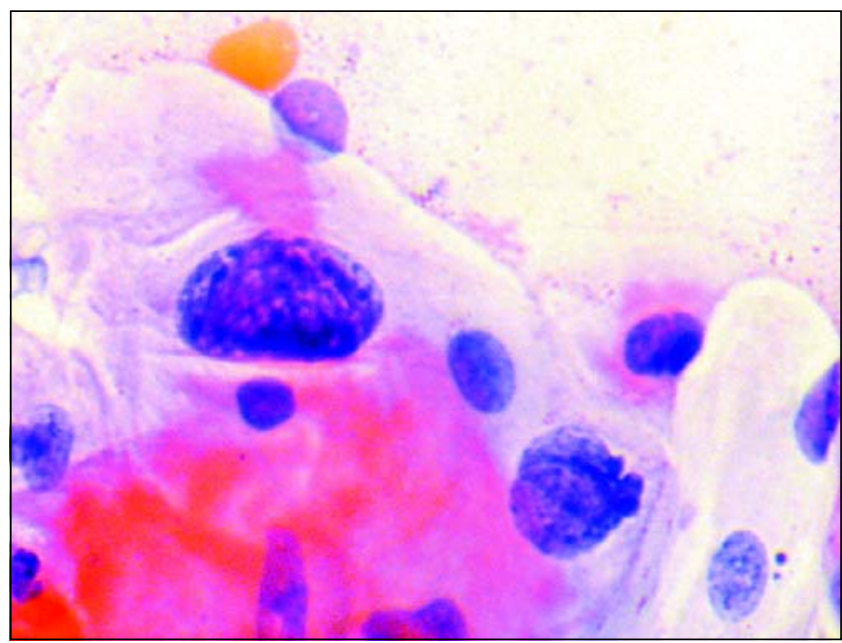

Figure 5. A: Transformation zone with papillomatose lesion rich in coilocytos (HE, 100x). B: Squamous epithelium hiperplasic.

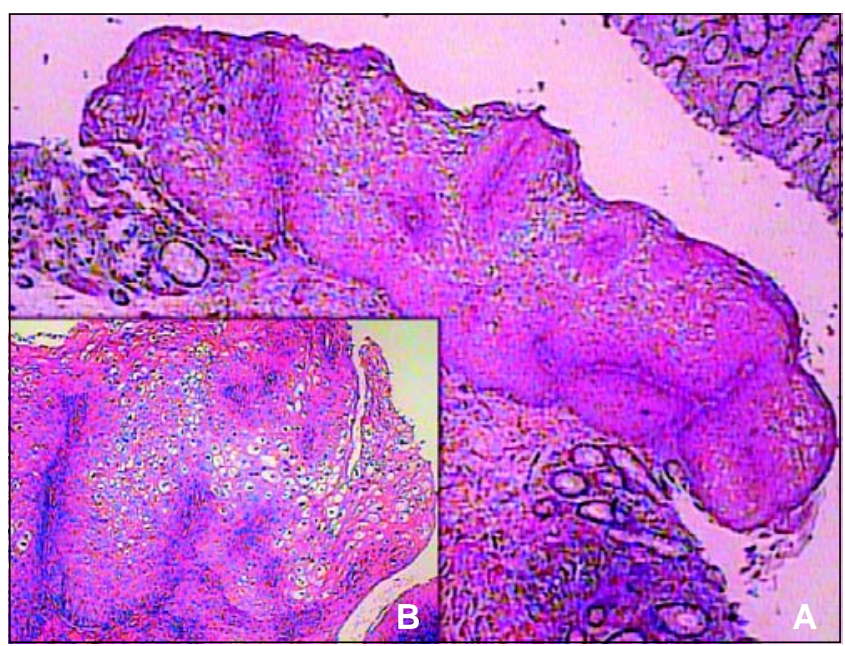

Figure 2. Gigant perianal condylomata.

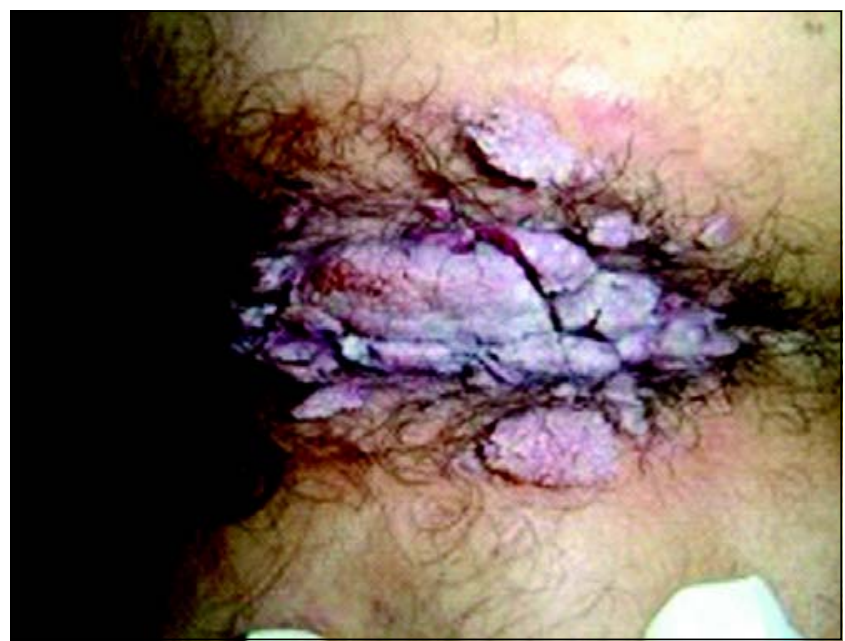

Figure 4. Anal cytology of low-grade squamous intraepithelial lesions-LSIL.

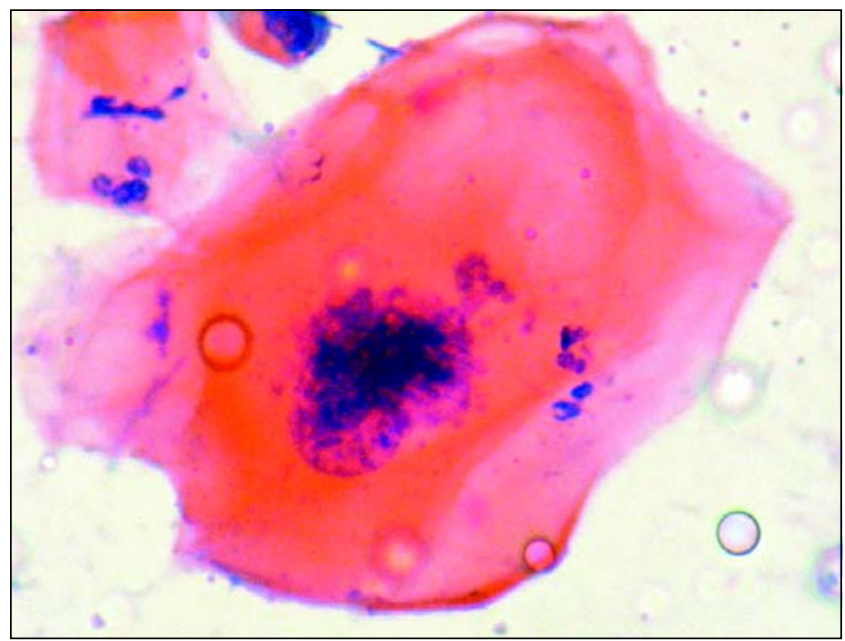

Figure 6. Neoplasm atipia in all malpighiano epithelium (AIN 3) (HE, 400x).

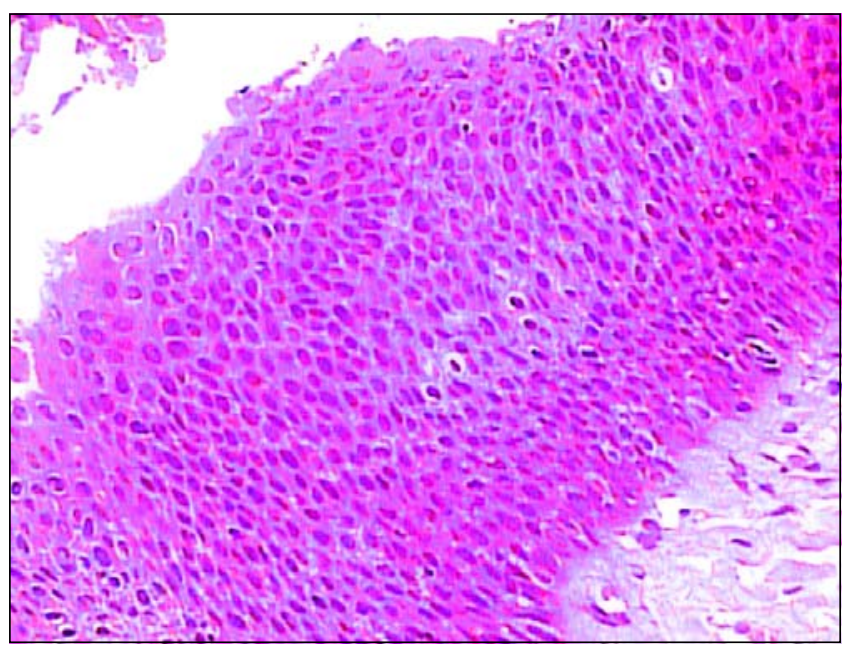


Table 2. Results of anuscopy under colposcopic vision

\begin{tabular}{lrr}
\hline Results & $\mathbf{N}$ & $\mathbf{\%}$ \\
\hline Findings suggestive of low-grade lesion & 10 & 47.6 \\
Flat acetowhite epithelium & 2 & \\
Flat acetowhite epithelium with fine mosaic & 2 & \\
Flat acetowhite epithelium with micropapillae & 1 & \\
Flat acetowhite epithelium + endoanal condylomata & 2 & \\
Flat acetowhite epithelium + endo and perianal condylomata & 1 & \\
Flat acetowhite epithelium with fine punctuation + endo and perianal cond. & 1 & \\
Flat acetowhite epithelium with fine punctuation + endoanal cond. & 1 & \\
Finding suggestive of high-grade lesion & 4 & \\
Dense acetowhite epithelium with thick mosaic & 3 & \\
Dense acetowhite epithelium with thick mosaic + endo and perianal cond. & 1 & \\
Condylomata acuminatum & 6 & \\
Endoanal & 2 & \\
Perianal & 1 & \\
Endo and perianal & 3 & $\mathbf{4 0 0 . 0}$ \\
Micropapillae & 1 & $\mathbf{2 1}$ \\
Total & & \\
\hline
\end{tabular}

\section{Discussion}

We conclude that anal examination of patients with HIV/ AIDS is important for the detection of premalignant lesions and that anuscopy under colposcopic vision and histology is better than anal cytology for the diagnosis of these lesions. Although there is no consensus on the best way to screen for anal cancer [17], we suggest anal cytology, followed by biopsy, guided by anuscopy under colposcopic vision, for the prevention and diagnosis of anal lesions mediated by HPV in high-risk groups, such as men with HIV/AIDS [18,19].

The patients enrolled in our study were young, with a mean age of 38.4 years, a finding similar to those of Varnai et al. and Wilkin et al., who observed that anal lesions mediated by HPV occurred mainly in young individuals, with a mean age of 42.2 years for men with a histological diagnosis of anal lesion [20] and 40 years or less as a risk factor for abnormal anal cytology and biopsy [21].

When we examined the clinical status of HIV disease, our patients generally had a good immunological status. This favorable immunological profile was a result of their treatment, which not only decreased mortality, but also increased incidence of anal cancer and other HPV-associated diseases due to their longer survival, a finding already described by other authors [11,19,21,22]. The use of HAART does not seem to modify the natural history of HIV-HPV co-infection [4,19,23].

Most of our patients identified themselves as homosexuals or bisexuals and most of them (61.9\%) reported more than 10 sexual partners of the same sex during their lifetime. Sexual behavior apparently contributed to the high frequency of HPVmediated anal lesions in this group. These behaviors are among the main risk factors for acquisition of co-infection, namely receptive anal intercourse and a large number of sexual partners [11,20,24-27]; this is the main route of transmission of HPV and HIV $[3,24,25]$ and is an important risk factor for AIN [3,4,28-30].

Surprisingly, $19 \%$ of the patients with an abnormal anal examination were heterosexuals. Piketty et al. and Frazer et al. also found that HPV infection and AIN can be acquired by individuals with HIV infection, even without receptive anal intercourse [24,31]. Among the heterosexuals who have not practiced anal intercourse, immunological instability caused by the HIV infection seems to be an important risk factor for the development of anal infection by HPV and AIN $[9,24,31,32]$.

Anuscopy under colposcopic vision proved to be of fundamental importance for detecting and identifying anal lesions and for determining the site of anal biopsy. Anuscopy is known for it role in the elucidation of abnormal cytology findings. All abnormalities detected with anuscopy should be biopsied $[1,10,33]$. We used the same cervical colposcopy technique as these previous studies. The anuscopic examination evaluated the rectal glandular epithelium, the squamous columnar joints, which are the site of most lesions, as well as the anal squamous epithelium. This exam also evaluated the perianal region. The main difficulty with this examination was management of the equipment. Every centimeter of the anorectal mucosa was evaluated through slow removal of the anuscope and repeated adjustment of the colposcopic focus when the acetic acid was applied to each segment of the mucosa. This requires much attention on the part of the examiner and cooperation of the patient.

It is recommended that insertion of the anuscope, and subsequent insertion of the gauze imbibed with acetic acid, be followed by withdrawal of the anuscope; three minutes later the gauze should be removed and the anuscope reinserted [34]. This technique, besides being uncomfortable, due to insertion of the anuscope at two different moments, causes detachment of the anorectal epithelium because of prolonged 
action of acetic acid; this makes evaluation difficult and distorts the limits between these layers of epithelium.

Although many studies indicate anal cytology as the principal examination technique for screening high-risk groups for AIN and anal cancer, its effectiveness is not well established [33-36]. Reported sensibility ranges between $69 \%$ and $93 \%$, with a specificity of between $32 \%$ and $59 \%$ [33-36]. These variations may be due to the methods used in the collection of anal specimens, the type of cytology technique employed or interand intra-observer variation between pathologists [10,32,33]. Anal cytology exams of our group of patients evidenced abnormalities in just $47.6 \%$ of the individuals with a lesion at anuscopy, and no HSIL was observed with cytology. The prevalence of abnormal cytology in HIV-positive men varies; whereas Moscicki et al. and Wilkin et al. found prevalence rates of $41.2 \%$ [9] and $48 \%$ [21], similar to what we found, Sirena et al. reported $75 \%$ abnormal cytologies [30].

The anuscopic findings correlated well with the biopsy results; in all the patients with anuscopic findings suggestive of high-grade lesions, this diagnosis was confirmed at histology. The main abnormalities associated with high-grade lesions in our patient group were dense acetowhite epithelium associated with thick punctuation or mosaic patterns. A previous study had similar findings; vascular alterations, such as punctuation and mosaics, were more frequently associated with high-grade AIN, while micropapillae and condylomata were more associated with low-grade AIN; a mosaic pattern was uncommon in low-grade lesions [12].

In a study of 186 anal biopsies of HIV-positive patients, among the 103 lesions with indication of an anal lesion < HSIL at anuscopy, 60 actually corresponded to a biopsy $<$ AIN 2 . Among the remaining 83 anuscopic findings suggestive of a lesion $\geq$ HSIL, 62 corresponded to a lesion $\geq$ AIN 2 at biopsy [37].

This study also showed that condylomata lesions are associated with both low-grade and high-grade lesions on histology, demonstrating the fundamental importance of investigating any abnormal anuscopic finding. Jay found that among anuscopic findings suggestive of condyloma, 91\% were really low-grade lesions at biopsy and 8\% high-grade AIN [12]. These findings reinforce the importance of investigating condylomatas, because they may hide a higher-grade lesion [10,12].

We found only a moderate degree of correspondence between the results of cytology and those of the histological examinations. Cytology showed alterations of lower intensity than those observed in the biopsies. Other authors also reported disagreement between cytology and biopsy results $[4,8]$. Arain et al. found an agreement of $90 \%$ between a diagnosis of HSIL and a high-grade AIN; however, when there was cytologic diagnosis of ASCUS and LSIL, there was only a 46\%-56\% likelihood of a high-grade AIN on biopsy [8]. Sanjose et al. reported that cytologic diagnosis of ASCUS is more frequently associated with AIN detection on biopsy and with anuscopic abnormalities [4]. The rate of discrepancy is high when compared with cervical cytology, in which ASCUS and LSIL are associated with a 5\%$17 \%$ likelihood of being a high-grade AIN on biopsy [38,39]. 
Lacey et al. also demonstrated that anal cytology tends to underestimate the grade of the lesion; the sensibility of anal cytology to detect an HSIL, which corresponds to a highgrade AIN on biopsy, is around 78\% [40]. However, Palefsy et al. found that the sensibility of cytology increased when it is carried out periodically in HIV-positive patients [34]. Likewise, Chin-Hong \& Palefsky have shown that the sensibility of anal cytology is greater in HIV-positive men, when compared with HIV-negative men, probably because HPV-mediated anal lesions are more common in this risk group [1].

\section{Conclusions}

Discrepancies were observed between the results of the three methods of examinations used in the diagnosis of HPVmediated anal lesions, especially for cytology, which underestimated the frequency and the grade of the lesions. These findings reinforce the importance of anuscopy under colposcopic vision for the detection of lesions and for determining the site of a biopsy. Considering that patients have few if any symptoms, routine use of these diagnostic methods is important for the prevention of anal squamous cancer in individuals with HIV/AIDS.

\section{References}

1. Chin-Hong P.V., Palefsky J.M. Human papillomavirus anogenital disease in HIV-infected individuals. Dermatologic Therapy 2005; $18: 67-76$.

2. Palefsky J.M., Holly E.A. Immunosuppression and co-infection with HIV. J Natl Cancer Inst Monogr 2003;3:41-6.

3. Berry J.M., Palefsky J.M. Anogenital neoplasia and HIV. HIV InSite Knowledge Base Chapter [serial on the Internet]. 1998 Nov [cited 2006 maio 13]. Available from: http:// www.hivinsite $\backslash$ Anogenital Neoplasia and HIV.htm.

4. de Sanjose S., Palefsky J. Cervical and anal HPV infection in HIV positive women and men. Virus Res 2002;89:201-11.

5. Steenbergen R.D., De Wilde J., Wilting S.M., et al. HPV-mediated transformation of the anogenital tract. J Clin Virol 2005;32S:S25-S33.

6. Palefsky J.M., Holly E.A., Gonzales J., et al. Detection of human papillomavirus DNA in anal intraepithelial neoplasia and anal cancer. Cancer Res 1991;51:1014-19.

7. Zaki S.R., Judd R., Coffield L.M., et al. Human papillomavirus infection and anal carcinoma. Retrospective analysis by in situ hybridization and the polymerase chain reaction. Am J Pathol 1992; $140: 1345-55$

8. Arain S., Walts A.E., Thomas P., Bose S. The anal Pap smear: cytomorphology of squamous intraepithelial lesions. Cytojournal 2005;2(4):1-7.

9. Moscicki A.B., Durako S.J., Houser J., et al. Human papillomavirus infection and abnormal cytology of the anus in HIV-infected and uninfected adolescents. AIDS 2003;17:311-20.

10. Leiman G. Anal screening cytology. Cytojournal [serial in the Internet]. 2005 [cited 2005 Jun 12]; 2-5. Available from: http/ /www.cytojournal.com/content/2/1/5.htm.

11. Palefsky J.M. Biology of HPV in HIV Infection. Adv Dent Res 2006;19:99-105.

12. Jay N. Colposcopic appearance of anal squamous intraepithelial lesions: relationship to histopathology. Dis Colon Rectum 1997; $40: 919-28$.

13. Singer A., Monaghan J.M. Colposcopia - Patologia e Tratamento do Trato Genital Inferior. 2nd ed. Rio de Janeiro: Revinter; 2002:73-102.

14. Solomon D., Davey D., Kurman R., et al. The 2001 Bethesda System. Terminology for reporting results of cervical cytology. JAMA 2002;287:2114-9.

15. Mello I.M. Terminologia Colposcópica. Uma análise crítica [serial on the Internet]. 2004. [cited 2005 Abr 20]. Available from: http://www.//colposcopia.org.br.htm.
16. Kreuter A., Brockmeyer N.H., Rochdorfer B., et al. Clinical spectrum and virologic characteristics of anal intraepithelial neoplasia in HIV infection. J Am Acad Dermatol 2005;52:603-8.

17. Cranston R.D., Darragh T.M., Holly E.A., et al. Self-collected versus clinican-collected anal cytology specimens to diagnose anal intraepithelial neoplasia in HIV-positive men. J Acquir Immune Defic Syndr 2004;36:915-20.

18. Palefsky J.M. Screening for anal and cervical dysplasia in HIVinfected patients. The PRN Notebook 2001;6(3):24-31.

19. Palefsky J.M., Holly E.A., Efirdc J.T., et al. Anal intraepithelial neoplasia in the highly active antiretroviral therapy era among HIV-positive men who have sex with men. AIDS 2005;19:1407-14.

20. Varnai A.D. HPV in anal squamous cell carcinoma and anal intraepithelial neoplasia (AIN). Impact of HPV analysis of anal lesions on diagnosis and prognosis. Inter J Colorectal Dis 2005;21:135-42.

21. Wilkin T.J., Palmer S., Brudney Kf., et al. Anal intraepithalial neoplasia in heterosexual and homosexual HIV-positive men with access to antiretroviral therapy. J Inf Dis 2004;190:1685-91.

22. Nadal S.R., Calore E.E., Manzione C.R., et al. Incidência de neoplasias intra-epiteliais anais em doentes HIV-positivos portadores de condilomas acuminados, comparando período anterior e posterior aos inibidores da protease. Rev Bras Coloproct 2005;25(3):217-22.

23. Palefsky J.M., Holly E.A., Ralstan M.L., et al. Effect of highly active antiretroviral therapy on the natural history of anal squamous intraepithelial lesions and anal human papillomavirus infection. Acquir Immune Defic Syndr 2001;28(5):422-8.

24. Piketty C., Darragh T.M., Heard J., et al. High prevalence of anal human papillomavirus infection and anal cancer precursors among HIV-infected persons in the absence of anal intercourse. Ann Intern Med 2003;138(6):453-9.

25. Schiffman M., Kjaer S.K. Chapter 2: Natural history of anogenital human papillomaviruses infection and neoplasia. J Natl Cancer Inst Monogr 2003;31:14-9.

26. Snoek E.M., Niesters H.G., Mulder P.G., et al. Human papillomavirus infection in men who have sex with men participating in a Dutch gay cohort study. Sex Transm Dis 2003;639-44.

27. Jin F., Prestage G.P., Kippax S.C., et al. Risk factors for genital and anal warts in a prospective cohort of HIV-negative homosexual men: The HIM study. Sex Transm Dis 2006;33(12):1-6.

28. Daling J.R., Weiss N.S., Hislop T.G. Sexual practices, sexually transmitted diseases, and the incidence of anal cancer. N Engl $\mathbf{J}$ Med 1987;317:973-7.

29. Palefsky J.M., Holly E.A., Jay N., et al. Anal cancer in gay and bisexual men. AIDS Res Instit 2000.

30. Sirena G., Videla S., Pinõl M., et al. High prevalence of human papillomavirus infection in the anus, penis and mouth in HIVpositive men. AIDS 2006;20(8):1201-6.

31. Frazer I.H., Cox J.T., Mayeaux E.J.J., et al. Advances in prevention of cervical cancer and other human papillomavirus-related diseases. Pediatr Infect Dis J 2006;25(2):S65-S81.

32. Fox P.A. Human papillomavirus and anal intraepithelial neoplasia. Curr Opin Infect Dis 2006;19:62-6.

33. Chiao E.Y., Giordano T.P., Palefsky J.M., et al. Screening HIVInfected Individuals for anal cancer precursor lesions: a systematic review. Clin Infect Dis 2006;43:223-33.

34. Palefsky J.M., Holly E.A., Hogeboom C.J., et al. Anal cytology as a screening tool for anal squamous intraepithelial lesions. J Acquir Immune Defic Syndr Hum Retrovirol 1997;14(5):415-22.

35. Fox P.A., Seet J.E., Stebbing J., et al. The value of anal cytology and human papillomavirus typing in the detection of anal intraepithelial neoplasia: a review of cases from an anoscopic clinic. Sex Transm Infec 2005;81:142-6.

36. Nadal S.R., Manzione C.R. Papilomavírus humano e o câncer anal. Rev Bras Coloproct 2006;26(2):204-7.

37. Mathews W.C., Sitapati A., Caperna J.C., et al. Measurement characteristics of anal cytology, histopathology, and high-resolution anoscopic visual impression in an anal dysplasia screening program. J Acquir Immune Defic Syndr 2004;37:1610-5.

38. Wright Tc J.R., Cox J.T., Massad L.S., Twiggs L.B., Wilkinson E.J. 2001 Consensus Guidelines for the management of women with cervical cytological abnormalities. JAMA 2002;287:2120-9.

39. The ASCUS-LSIL Triage Study (ALTS) Group. A randomized trial on the management of low-grade squamous intraepithelial lesion cytology interpretations. Am J Obstet Gynecol 2003;188:1393-1400.

40. Lacey H.B., Wilson G.E., Tilston P., et al. A study of anal intraepithelial neoplasia in HIV positive homosexual men. Sex Transm Inf 1999;75:172-7. 